\title{
COMPARATIVE STUDY BETWEEN OUTCOMES OF TUBULARIZED INCISED PLATE URETHROPLASTY AND MODIFIED TUBULARIZED INCISED PLATE URETHROPLASTY IN THE MANAGEMENT OF DISTAL HYPOSPADIAS
}

\author{
MA SALAM ${ }^{1}$, M ASADUZZAMAN $^{1}$, MR QUDDUS ${ }^{2}$, AMAR CHOUUDHURY $^{1}$, MD. FAISAL ISLAM $^{1}$, \\ MD. WALIUL ISLAM ${ }^{1}$, MD. NURUL HOODA ${ }^{1}$, SM MAHBUB ALAM ${ }^{3}$ \\ ${ }^{1}$ Department of Urology, National Institute of Kidney Diseases and Urology, Sher-e-Bangla Nagar, Dhaka, ${ }^{2}$ Department of \\ Surgery, Satkhira Sadar Hospital, Satkhira, ${ }^{2}$ Department of Urology, Dhaka Medical College \& Hospital
}

\begin{abstract}
Objective: To compare the outcomes of tubularized incised plate urethroplasty and modified tubularized incised plate urethroplasty in the primary management of distal hypospadias

Materials and Methods: Total 70 patients of age group 2 to 10 years with distal hypospadias were selected for this study from January 2008 to December 2010. They were divided into Group-A ( $n=35)$ treated by the tubularized incised plate urethroplasty and Group-B $(n=35)$ treated by the modified tubularized incised plate urethroplasty. The modification was performed by using inner preputial skin on the incised plate before tubularization. All patients were followed up immediately and at $4^{\text {th }}, 8^{\text {th }}$ and $12^{\text {th }}$ weeks after operation.
\end{abstract}

Results: The satisfactory cosmetic and functional outcomes were observed in 29 patients (82.85\%) of Group-A and all families of Group-B were happy with aesthetic and functional outcomes. Urethrocutaneous fistula developed in 5 patients (14.70\%) patients of Group$A$ and 1 (2.94\%) patient in Group-B. Three patients (8.82\%) in group-A and one patient (2.94\%) in group-B were found to develop meatal stenosis. One patient (2.94\%) developed stricture urethra in group $A$ but no patient in group-B developed urethral stricture. Overall complications occurred in 10 patients (29.41\%) in Group-A and 2 patients (5.88\%) in Group-B.

Conclusions: This study demonstrates that modified tubularized incised plate urethroplasty had excellent cosmetic and functional outcomes and fewer complications than that of tubularized incised plate urethroplasty in the primary management of distal hypospadias.

Keywards: Tubularized incised plate urethroplasty technique, modified tubularized incised plate urethroplasty, primary repair, distal hypospadias.

Bangladesh J. Urol. 2014; 17(2): 75-81

\section{Introduction:}

Hypospadias is a congenital abnormality in which the urethral meatus is positioned either along the ventral shaft of the penis or on the scrotum or perineum instead of being located at the tip of the penis. About $70 \%$ of all cases of hypospadias are distal penile variety[1]. Modern standards for all distal hypospadias repair should include

Address of Correspondence: Md. Abdus Salam, Department of Urology, National Institute of Kidney Diseases and Urology, Dhaka, Email: masalam.uro@gmail.com both a good functional and cosmetic reconstruction, in a suitable one stage procedure[2]. Over the years, more than 200 techniques have been described[3]. It is not surprising it represents a spectrum of disease for which no single method of repair is applicable. In 1994, Snodgrass described tabularized incised plate urethroplasty for the correction of distal hypospadias[4]. A concern is that the relaxing incision of the urethral plate is equivalent to internal urethrotomy, which may produce scar rather than epithelialized, leading to 
neourethral stricture or meatal stenosis[5]. To avoid healing problem at the raw surface of the neourethra in Snodgrass method, many authors suggested that the incised raw area should be covered with an epithelialized surface. They performed a modified version of Snodgrass procedure in which a free graft harvested from the inner prepuce was sutured onto the incised plate and claimed better results in terms of complications like meatal stenosis, urethral stricture and urethrocutaneous fistula $[6,7,8]$. This study was conducted to compare the outcomes of tubularized incised plate urethroplasty and modified tubularized incised plate urethroplasty in the primary management of distal hypospadias.

\section{Materials and Methods:}

This study was conducted in the department of Urology, National Institute of Kidney Diseases \& Urology and Dhaka Medical College Hospital and some private hospitals in Dhaka city from January 2008 to December 2010. Total 70 patients of age group 2 to 10 years with distal hypospadias were selected for the study. They were divided into Group-A $(n=35)$ treated by the tubularized incised plate urethroplasty and Group-B $(n=35)$ treated by the modified tubularized incised plate urethroplasty.All patients were evaluated by taking detailed history, physical examinations and investigations like urine analysis, blood biochemistries, chest skiagram, bleeding time (BT) \& clotting time (CT) and ultrasonography of KUB region to identify type of hypospadias and to exclude the associated congenital anomaly and co-morbid diseases.
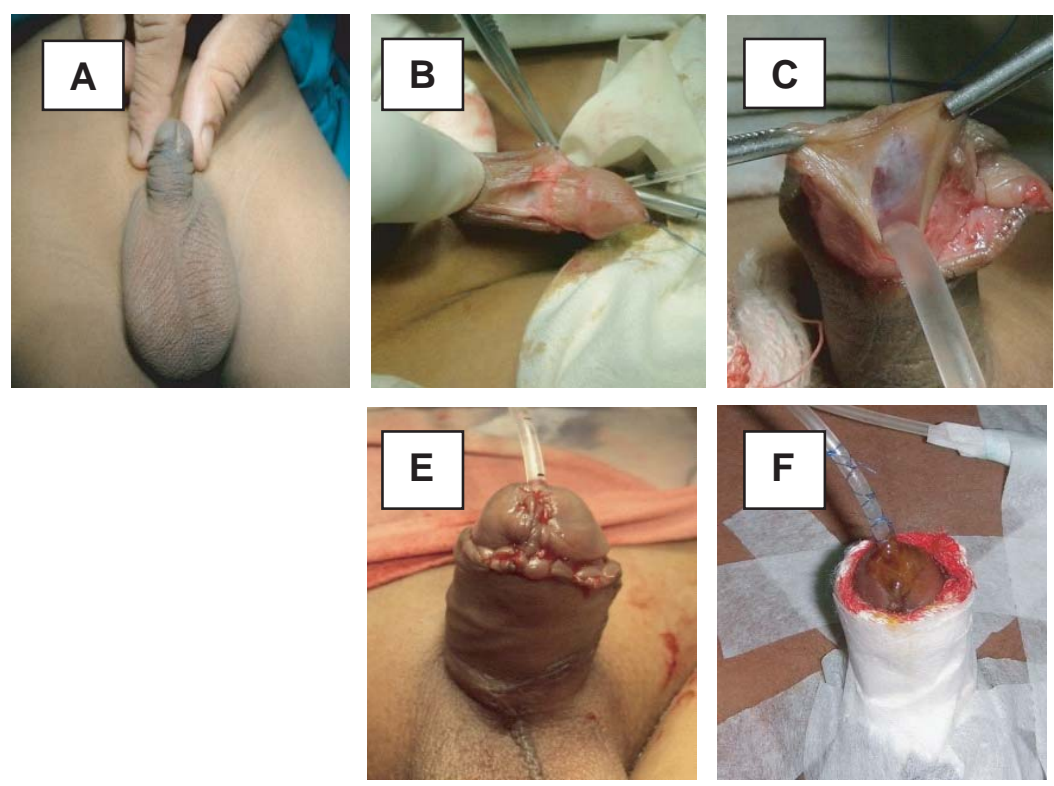

\section{Surgical technique:}

All patients underwent surgery under general anaesthesia. The surgical procedure began with the placement traction suture on glans with 5-0 prolene and insertion of a $6 \mathrm{Fr}$ catheter or feeding tube ( $8 \mathrm{Fr}$ to $10 \mathrm{Fr}$ catheters for boys older than 5 years). A circumferential incision was made 5 to $7 \mathrm{~mm}$ proximal to the coronal margin and $2 \mathrm{~mm}$ proximal to the hypospadiac meatus to deglove the penis for the correction of chordee. An artificial errection test was performed and if needed penis was straightened by Nesbit plications. A tourniquet was placed at the root of the penis to minimize the bleeding. The lateral margins of the urethral plate were separated from the glans by parallel longitudinal incisions approximately 7 to $9 \mathrm{~mm}$ apart, creating glanular wings. Gentle traction along the edges of the urethral plate delineated its midline which was incised from the hypospadiac meatus distal to the end of plate. This was the key step of the tubularized incised plate urethroplasty (Snodgrass procedure), which widens the plate and allows tubularization without additional skin flaps.

The incision typically extends through the mucosal and sub-mucosal tissues of the urethral plate down to the corporal bodies, as described by Snodgrass dividing the plate into 2 epithelial strips which was closed ventrally over a $6 \mathrm{Fr}$ stent (8Fr to $10 \mathrm{Fr}$ stent for boys older than 5 years). But in modified tubularized incised plate urethroplasty, a small graft was taken from the excess inner preputial skin normally from dorsal preputial hood and was laid as a free graft in the dorsal urethral

Fig.-1: Tubularized Incised Plate Urethroplasty

A- Sub coronal hypospadias, B-Circumferential incision just below the corona, C-Incision of the urethral plate from hypospadiac meatus to tip of the penis, D-Tubularization of urethral plate, E-Completion of the glanuloplasty, F-Dressing applied. 

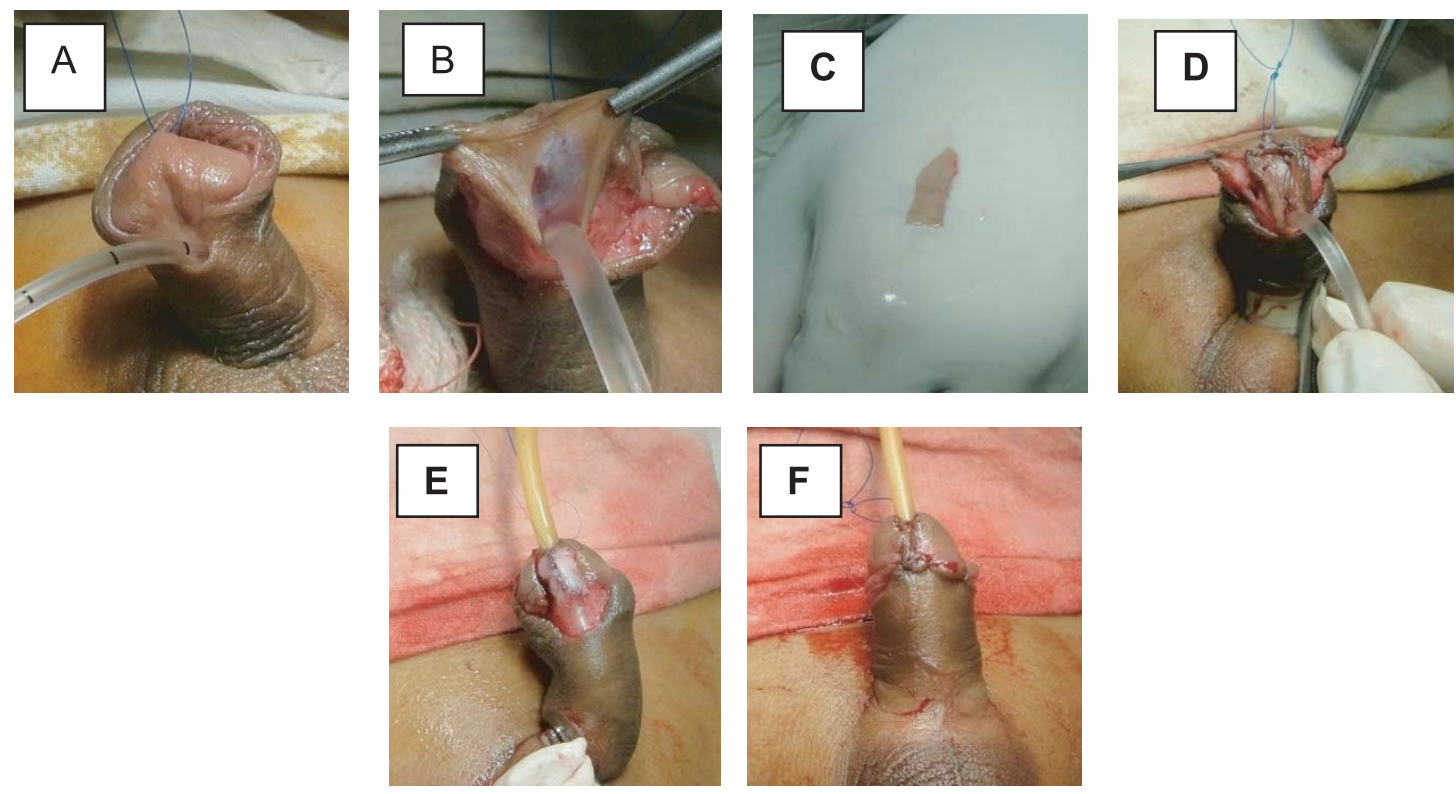

Fig.-2: Modified Tubularized Incised Plate Urethroplasty

A-Sub coronal hypospadias, traction suture at the glans,B- Incision given on the urethral plate, C- Graft taken from inner preputial skin, D- Graft was placed on the raw area of urethral plate, E- Tubularization of the urethral plate, F- Glanuloplasty was done, completion of skin coverage.

defect. In both cases tension free water tight tubularization was performed over a 6 Fr catheter or feeding tube (8Fr to $10 \mathrm{Fr}$ for boys older than 5 years), using running suture with 6-0/7-0 polygalactin in 2 layers. Closure of the $1^{\text {st }}$ layer was done with efforts made to invert the epithelium completely. The $2^{\text {nd }}$ layer incorporates carefully preserved periurethral vascularized tissue. The vascularized dorsal dartos flap was transposed ventrally to cover enter new urethra. The new urethral meatus was then approximated with the glans by a few interrupted sutures.

Finally, the bared penile shaft was covered with the mobilized skin by 4-0/5-0 absorbable suture. Pressure dressing was applied over the wound to prevent haematoma. The urethral stent was kept indwelling for 10-14 days and removed thereafter. All patients received post operative analgesics, antibiotics, sedatives and anticholenergic drugs. When recovery was uneventful, patients were usually discharged on the $4^{\text {th }}$ to $5^{\text {th }}$ post operative day.Subsequent follow-up was done in outpatient department.

\section{Results and Observation:}

Total 70 patients were prepared for final data analysis. Distribution of age of both Group A and Group B was between 2 to 10 years. 21 patients (60.0\%) in Group A and 19 patients (54.28\%) in Group-B presented with sub-coronal variety of hypospadias. 14 patients (40. 0\%) in Group A and 16 patients (45.72\%) in Group-B presented with distal penile variety of hypospadias. 22 patients (62.85\%) in Group-A and 23 patients (65.72\%) in Group-B presented with mild chordee. 13 patients (37.15\%) in Group-A and 12 patients (34.28\%) in Group$B$ presented with no chordee. The mean $( \pm S D)$ duration of operation time was $78.68 \pm 9.07$ minutes (Range: 60 100 minutes) in Group-A and 92.79 \pm 12.88 minutes (75120 minutes) in Group-B. Cosmetic appearance of glans was conical and neo-meatus was slit like and accepted in all patients in both Group-A and Group-B.

Neo-meatus encroached in ventral granular surface in 3 patients (8.57\%) in Group-A and were unsatisfactory to the parents. Neo-meatal location was satisfactory in other 32 patients (91.43\%) in Group-A and all 35 patients in Group-B. 4 patients (11.42\%) in Group-A had narrow and deflected urinary stream but rest of the patients (88.78\%) in Group-A and all 35 patients in Group-B had satisfactory straight urinary stream. So, satisfactory cosmetic and functional outcome was observed in 29 patients (82.85\%) in Group-A and only 6 patients (17.15\%) had unsatisfactory outcome. In Group-B all 35 patients had satisfactory outcome (Table I). 
Table-I

Satisfactory cosmetic and functional outcome

\begin{tabular}{|c|c|c|c|c|}
\hline Satisfactory Outcome & $\begin{array}{c}\text { Group-A }(n=35) \\
\text { No }(\%)\end{array}$ & $\begin{array}{c}\text { Group-B }(n=35) \\
\text { No }(\%)\end{array}$ & $\begin{array}{c}\text { Calculated } \\
\text { value }\end{array}$ & $\begin{array}{c}\mathrm{P} \\
\text { value }\end{array}$ \\
\hline Present & $29(82.85 \%)$ & $35(100 \%)$ & 6.581 & 0.025 \\
\hline Absent & 06(17.15\%) & $0(0 \%)$ & & \\
\hline
\end{tabular}

Immediate postoperative follow-up during hospital stay showed wound dehiscence in I patient (2.85\%) of Group$A$ and in Group-B there was no wound dehiscence. Urethrocutaneous fistula developed in 3 patients (8.57\%) of Group-A and 1 patient (2.85\%) of Group-B during hospital stay (Table-II).

2 patients (5.71\%) of Group-A were found to develop urethrocutaneous fistula at $4^{\text {th }}$ week after surgery but in Group-B no urethrocutaneous fistula was observed in the subsequent follow-up. Three patients (8.577\%) of group-A and one patient (2.85\%) of group-B were found to develop meatal stenosis at subsequent follow-up. One patient (2.85\%) of group-A was found to develop urethral stricture at $8^{\text {th }}$ week but no urethral stricture was present in Group-B at scheduled follow up.

One patient who developed wound dehiscence at immediate postoperative period, healed by conservative treatment and advised for re-operation after 6 months. 4 patients who developed meatal stenosis were advised to do regular dilatation. Three of them responded well but meatal stenosis persisted in one patient till last follow- up and was advised for meatoplasty. One patient who developed urethral stricture also advised for regular dilatation but urethral stricture persists in till last followup and was advised for re-operation.

Table-II

Immediate postoperative complications

\begin{tabular}{lcccc}
\hline Complications & Group-A $(n=35)$ & Group-B $(n=35)$ & Calculated & value \\
& No $(\%)$ & No $(\%)$ & value \\
\hline Wound dehiscence & $1(2.94)$ & $0(0)$ & 1.015 & 1.00 \\
Urethrocutaneous fistula & $3(8.82)$ & $1(2.94)$ & 1.063 & 0.614 \\
\hline
\end{tabular}

Table-III

Late postoperative complications

\begin{tabular}{|c|c|c|c|c|c|c|c|c|}
\hline \multirow[t]{2}{*}{ Complications } & \multicolumn{4}{|c|}{ Group-A (n=35) } & \multicolumn{4}{|c|}{ Group-B $(n=35)$} \\
\hline & $4^{\text {th }}$ week & $8^{\text {th }}$ week & $12^{\text {th }}$ week & Total & $4^{\text {th }}$ week & $8^{\text {th }}$ week & $12^{\text {th }}$ week & Total \\
\hline Urethrocutaneous fistula & 2 & 0 & 0 & 2 & 0 & 0 & 0 & 0 \\
\hline Meatal stenosis & 0 & 2 & 1 & 3 & & 1 & 0 & 1 \\
\hline Urethral stricture & 0 & 0 & 1 & 1 & 0 & 0 & 0 & 0 \\
\hline
\end{tabular}

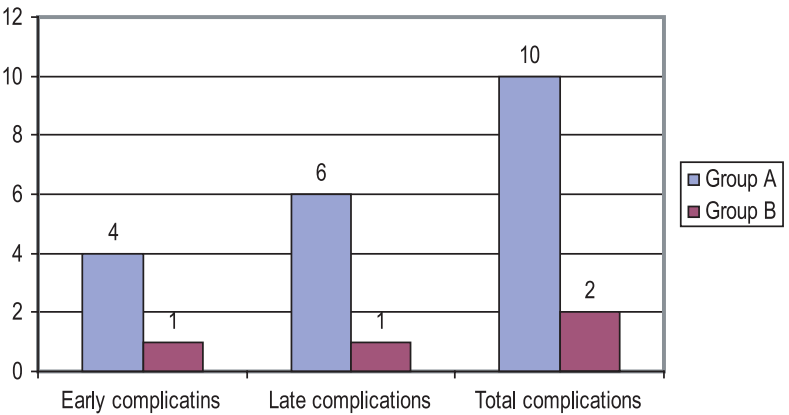

Fig.-4: Early complications, late complications and total complications of tubularized incised plate urethroplasty and modified tubularized incised plate urethroplasty
It is shown that overall complications occurred in 10 patients (28.57\%) those were treated by tubularized incised plate urethroplasty and 2 patients (5.71\%) those were treated by modified tubularized incised plate urethroplasty (urethral plate augmentation technique). After applying a test of significant for the complications following urethroplasty by Fisher's Exact test, $P$ value was observed $<0.023$, which means that the surgical outcome of the hypospadias surgery between two groups (Group A and Group B) is significantly different. 


\section{Discussion}

The surgical objectives of modern hypospadiology should include complete straightening of the penis, creating a hairless, smooth urethra of uniform caliber with the position of the meatus at the tip of the glans, normalization of voiding and erection, and normal appearance of the penis with a minimum of complications. Regardless of the severity of the malformation, urologists strive to meet such demands. As a result, over 200 described operative procedures or modifications have emerged to manage boys with hypospadias, but no single procedure has been considered a panacea for all types of hypospadias, and it has remained one of the most challenging problems in urological surgery. Tubularized incised plate urethroplasty is based on the principle of closure of the urethral plate ventrally in the midline, over a urethral stent, after having made a deep sagittal release incision on the midline of the urethral plate. A potential advantage of the repair is the formation of a vertical slit like neomeatus with good urethral caliber and tension free closure[5]. Jordan and Schlassberg described the natural history of wound healing; in epithelial apposition the wound heals by primary intention. In the absence of epithelial continuity or apposition, healing occurs by secondary intention and the epithelium progresses slowly from the edges of the wound, covering the raw area[9]. A concern is that the relaxing incision of the urethral plate is equivalent to internal urethrotomy, which may produce scar rather than epithelialize, leading to neourethral stricture or meatal stenosis[5]. To avoid healing problem at the raw surface of the neourethra in Snodgrass method, many authors suggested that the incised raw area should be covered with an epithelialized surface. They performed a modified version of Snodgrass procedure (modified tubularized incised plate urethroplasty) in which a free graft harvested from the inner prepuce was sutured onto the incised plate and claimed better results in terms of complications like meatal stenosis and urethrocutaneous fistula[8]. Kolon and Gonzales also performed a modified version of Snodgrass procedure in which a free graft harvested from the inner prepuce was sutured onto the incised plate and claimed better results in terms of complications like meatal stenosis and urethrocutaneous fistula as it has the added advantage of preservation of the urethral plate without any insult to its vascularity[10].

The mean $( \pm S D)$ duration of operation time was $78.68 \pm 9.07$ minutes (range: $60-100$ minutes) in GroupA and $92.79 \pm 12.88$ minutes (75-120 minutes) in Group-
$B$ in this study. The mean difference between the two groups showed statistically not significant ( $P$ value0.099). Other authors reported that the mean duration of their surgery was 57.4 (range 45-75) minutes in TIP urethroplasty and 87(range 35-170) minutes in graft tubularized incised plate urethroplasty[11,12]. In this study, feeding tube or small size catheter were used as a stent and diversion of urine and kept for 10-14 days. One patient in Group-B lost the feeding tube accidentally on $5^{\text {th }}$ postoperative day but he recovered without any complication.

Cosmetic appearance of glans was conical and neomeatus was slit like and satisfactory in all patients in both Group-Aand Group-B in present study. Neo-meatus encroached in ventral granular surface in three patients (8.82\%) in Group-A and were unsatisfactory to the parents. Neo-meatal location was satisfactory in other 31 patients (91.18\%) in Group-A and all 34 patients in Group-B. Three patient (8.82\%) in Group-A had deflection in urinary stream but rest of the patients (91.18\%) in Group-A and all 34 patients in Group-B had satisfactory straight urinary stream. Over all satisfactory cosmetic and functional outcome was observed in 28 patients (82.35\%) in Group-A and in Group-B all 34 patients had satisfactory outcome. In 2003, Sinha et al. reported that good cosmetic results were obtained in 42 out of 45 (93.3\%) patients and functional outcomes as judged by urinary stream was good in 41(93.3\%) patients; in 2005, Singh et al. reported that excellent cosmetic results were seen in $44(84.6 \%)$ patients and good functional results were seen in $46(88.8 \%)$ patients in their series of Snodgrass procedure for distal hypospadias[11,13]. Another study showed that all families were happy with penile aesthetic appearance after graft tubularized incised plate urethroplasty for distal hypospadias[14]. In this study cosmetic and functional outcome between the two groups showed statistically significant difference (P value- 0.025$)$.

One patient (2.9\%) developed wound dehiscence in Group-A and no wound dehiscence was found in Group$B$ in this study. Wound was healed on subsequent followup by regular dressing and appropriate antibiotics and parents were asked for re-operation after 6 months of first surgery. Other studies showed that wound dehiscence were observed $2.2 \%, 1.9 \%$ and $3 \%$ in Snodgrass procedure in distal hypospadias repair[1113]. But no wound dehiscence was observed in modified tubularized incised plate (TIP) urethroplasty[10,12]. 
Urethrocutaneous fistula developed in 5 patients (14.70\%) patients of Group-A and 1 (2.94\%) patient in Group-B. This result is comparable with published report in literatures the fistula rate was $2-14 \%, 9.6 \%$ and $16 \%$ in TIP urethroplasty but $9.52 \%$ and no fistula was observed in graft tubularized incised plate urethroplasty for distal hypospadias[5,12,13,15].

Three patients (8.82\%) in group-A and one patient (2.94\%) of group-B were found to develop meatal stenosis. Four patients who developed meatal stenosis were advised to do regular dilatation. Three of them responded well but meatal stenosis persisted in one patient till last follow- up and was advised for meatoplasty. Above results are compatible with other literatures where meatal stenosis was found $9 \%, 6.86 \%$ in TIP urethroplasty, and 3.3\%, no meatal stenosis was found in graft urethroplasty for distal hypospadias $[10,12,14,16]$.

One patient (2.94\%) developed stricture urethra in group A. He was also advised for regular dilatation but urethral stricture persists in till last follow-up and was advised for re-operation. Ghali reported similar result of $3 \%$ stricture in TIP urethroplasty[17]. But no patient in group$B$ developed urethral stricture, because the raw area had been completely eliminated by immediate grafting in group-B. This finding is comparable with report published in literatures where no stricture was found in graft TIP urethroplasty for distal hypospadias $[10,16]$.

In this study it is shown that overall complications occurred in 10 patients (29.41\%) those were treated by tubularized incised plate urethroplasty and 2 patients $(5.88 \%)$ those were treated by modified tubularized incised plate urethroplasty (urethral plate augmentation technique). In the literatures similar result of the overall complication rate was $12-33 \%$ in TIP urethroplasty procedure but complication rate was $15.5 \%$ and no complication was observed in graft TIP urethroplasty for distal hypospadias[10,12,13,18-20].

This study demonstrates that modified tubularized incised plate urethroplasty had excellent cosmetic and functional outcomes and fewer complications than tubularized incised plate urethroplasty. Although modified tubularized incised plate urethroplasty required 15-20 minutes extra time during operation for harvesting and grafting but this extra time did not affect postoperative outcomes. $P$ value was observed $<0.023$, which means that the overall surgical outcomes of the hypospadias surgery between two groups (Group A and Group B) is significantly different.

\section{Conclusion:}

The goal of modern hypospadias surgery is a functional neourethra that appears to be normally circumcised penis. Tubularized incised plate urethroplasty is a widely applicable technique for distal hypospadias repair. But in this study the modification was performed by using inner preputial skin on the incised plate before tubularization as dorsal free graft has low complication rate and excellent cosmetic results superior to tubularized incised plate urethroplasty. However, these results must be further evaluated by comparison study of large series.

\section{Conflict of Interest : None declared}

\section{References:}

1. McAninch JW 2008, 'Disorders of the Penis \& Male Urethra', in Tanagho EA, McAninch JW (eds):Smith's General Urology, $17^{\text {th }}$ edn, McGrawHill Companies, New York, pp. 625-637.

2. Cristian, K \& Keitil, S 2008, 'High odds for freedom from early complications after tabularized incised plate urethroplasty in 1 year old versus 5 years old boys', Journal of pediatric Urology, vol. 4, pp. 452-456.

3. Marshall, FF, Kavoussi, LR, McAninch, JW \& Peters, CA 1996, 'Text Book of Operative Urology, $1^{\text {st }}$ edn, WB Saunders, Philadelphia, pp. 902-908.

4. Snodgrass, W 1994, 'Tubularized incised plate urethroplasty for distal hypospadias', J Urol, vol.151, pp. 464-465.

5. Snodgrass, WT, Koyle, M, Manzoni, G, Hurwitz, R, Caldamone, A\& Ehrlich, R 1998, 'Tubularized incised plate hypospadias repair for proximal hypospadias', J Urol, vol.159, pp.2129-2131.

6. Decter, RM \& Franzoni, DF 1999, 'Distal hypospadias repair, the modified Thiersch-Duplay technique with or without hinging the urethral plate: a near ideal way to correct hypospadias', J Urol, vol. 162, pp. 1156-1158.

7. Kolon, TF \& Gonzales, ET 2000, 'The dorsal inlay graft for hypospadias repair, J Urol, vol. 163, pp. 1941-1943

8. Angelo, AB, Johathan, $R$, Nicholas, D \& Robert, $K$ 2005, 'Modified tubulanted incised plate urethroplasty (Snodgrass) procedure for hypospadias repair', J Urol, vol. 66, pp.1305-1306. 
9. Jordan, GH \& Schlassberg, SM 2002, 'Surgery of the Penis and Urethra', in Walsh, PC, Retik, AB, Vaughan, ED \& Wein, AJ (eds): Campbell's Urology, $8^{\text {th }}$ edn, WB Saunders company, Philadelphia, vol. 4, pp. 3886-3952.

10. Gangopadhyay, Sharma \& Mongha 2005, 'Onlay free preputial graft for mid and distal penile hypospadias', Journal of Indian Association of Plstic Surgeons, vol. 10, pp. 244-247.

11. Sinha RS, Saha, K, Bhattacharjee, PK \& Majhi, TK 2003, 'Snodgrass TIP in distal and mid penile hypospadias', J Indian Assoc Pediatr surg, vol. 8, pp. 226-230.

12. Fabio, F, Santiago, V, Alessandro, B, Pietro, A \& Luisa M 2009, 'Snodgrass Urethroplasty: Grafting the Incised Plate-10Years Later', J Urol, vol. 183, pp. 1730-1735.

13. Singh, N, Sharma, E, Saraf, R \& Goswamy, HL 2005, 'Tubularized incised plate urethroplasty for distal penile hypospadias-a regional centre experience', Indian J Urol, vol. 21, pp. 109-111.

14. Gamal Al-Saied \& Ahmed Gamal 2009, 'Versatility of tubularized incised plate urethroplasty in the management of different types of hypospadias: 5year experience', Afr J Paediatr Surg, vol. 6, no. 2, pp. 88-92.
15. Jiajie XE, Senkai LI, Yangqun LI, Qiang LI, Liqiang LIU \& Yongqian W 2005, 'Lengthening urethral plate with inner preputial skin graft: A modification of the onlay technique', J Urol, vol.173, no.1, pp.202-203.

16. Singh, RB \& Pavitran, NM 2004, 'Lessons learnt from Snodgrass tip urethroplasty: a study of 75 cases', Peditr Surg Int, vol. 20, pp. 204-206.

17. Ghali, AM 1999, 'Hypospadias repair by skin flaps: a comparison of onlay preputial with either Mathieu's meatal based or Duckett's tubularized preputial flaps', BJU Int, vol. 83, pp. 1032-1038.

18. Chen, SC, Yang, SS, Hsieh, CH \& Chen, YT 2000, 'Tubularized incised plate urethroplasty for proximal hypospadias', BJU Int, vol. 86, pp. 1050-1053.

19. Borer, JG, Bauer, SB \& Peters 2001, 'Tubularized incised plate urethroplasty: expanded use in primary and repeat surgery for hypospadias', J Urol, vol. 165, pp. 581-585.

20. Marte, A, di lorio, G, de Pasquale, Cortufo, AM \& di Meglio, D 2001, 'Functional evaluation of tubularized-incised plate repair of midshaft proximal hypospadias using uroflowmetry', BJU Int, vol. 87, pp. 540-43.

\section{Abbreviations:}

TIP : Tubularised Incised Plate 